UCRL-JC-115804

PREPRINT

\title{
Effects of Natural Gas Composition on Ignition Delay Under Diesel Conditions
}

\author{
J.D. Naber and D. L. Siebers \\ Sandia National Laboratories \\ Livermore, CA 94551-0969
}

\section{S.S. Di Julio}

California State University-Northridge

Northridge, CA 91330

\section{C.K. Westbrook}

Lawrence Livermore National Laboratory

Livermore CA; 94550

This paper was prepared for submittal to the Twenty-Fifth International Symposium on Cumbustion

UC Irvine, Irvine CA July 31-Aug 5, 1994

December 3, 1993

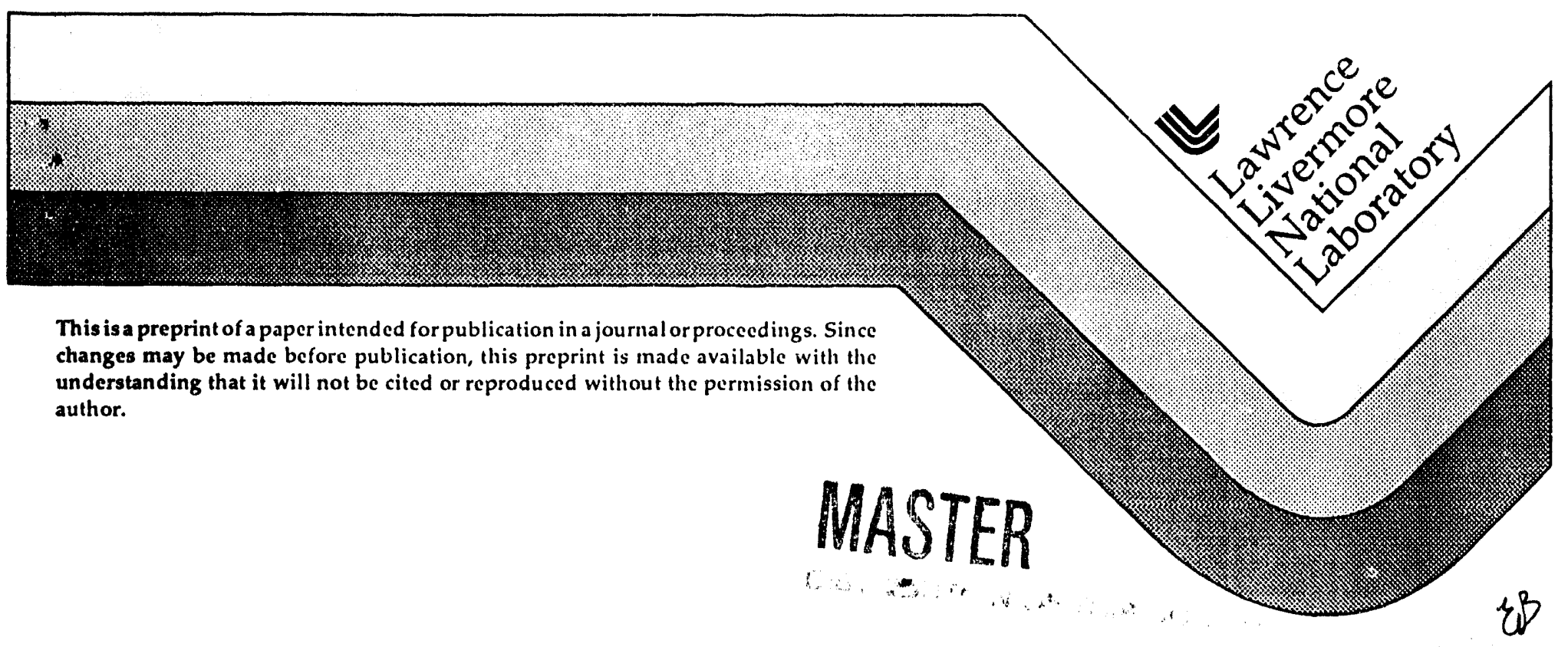

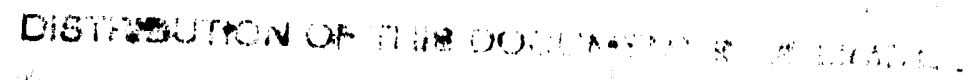
if. 


\section{DISCLAIMER}

Thls docuineat was prepared as an account of work spovesored by an ageacy of the United States Governenent. Neitber the United States Government ser the Univerdity of Callfornia ser any of thetr employees, ankes any warranty, express or implied, of

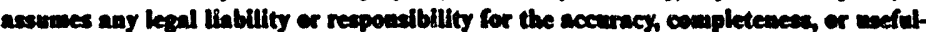

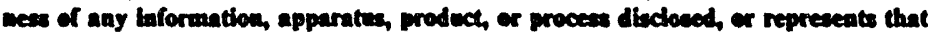
its use would oot lafringe privately ewaed rights. Reference berein to any specilic commercial producter, proceste, ex service by trade anme, trademark, manufacturer, or

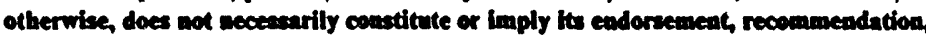
or favering by the United States Governanent or the Uaiversity of Callforaln. The views and opinions of authors expressed berein do wot wecesearily state er reflect those of the Umited States Goverument or the University of Callforula, and shall wot be wed for advertising or product eadorsemeat purposes. 


\title{
Effects of Natural Gas Composition on Ignition Delay Under Diesel Conditions
}

\author{
J.D. Naber \\ and \\ D.L. Siebers \\ Combustion Research Facility \\ Sandia National Laboratories \\ Livermore, CA 94551-0969 \\ S.S. Di Julio \\ California State University-Northridge \\ School of Engineering and Computer Science \\ Department of Mechanical Engineering \\ Northridge, CA 91330 \\ C.K. Westbrook \\ Lawrence Livermore National Laboratory \\ P.O. Box 808 \\ Livermore, $C A 94550$
}

\begin{abstract}
Effects of variations in natural gas composition on autoignition of natural gas under direct-injection (DI) diesel engine conditions were studied experimentally in a constant-volume combustion vessel and computationally using a chemical kinetic model. Four fuel blends were investigated: pure methane, a capacity weighted mean natural gas, a high ethane content natural gas, and a natural gas with added propane typical of peak shaving conditions. Experimentally measured ignition delays were longest for pure methane and became progressively shorter as ethane and propane concentrations increased. At conditions characteristic of a DI compression ignition natural gas engine at Top Dead Center (CR=23:1, $p=6.8 \mathrm{MPa}, T$ $=1150 \mathrm{~K})$, measured ignition delays for the four fuels varied from $1.8 \mathrm{~ms}$ for the peak shaving and high ethane gases to $2.7 \mathrm{~ms}$ for pure methane. Numerically predicted variations in ignition delay as a function of natural gas composition agreed with these measurements.
\end{abstract}

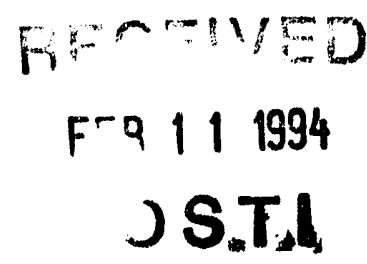




\section{Introduction and Background}

Use of natural gas (NG) as a diesel fuel has been growing in recent years. Natural gas provides advantages over conventional diesel fuels by reducing soot and other pollutant emissions. However, chemical composition of commercial natural gas can vary widely [1], with concentration extremes of $75-98 \%$ for methane, $0.5-13 \%$ for ethane and $0-2.6 \%$ for propane. For peak shaving practices with added propane, composition variations are even more extreme with methane levels as low as $56 \%$ and propane concentrations as high as $24 \%$. Composition variability has a great influence on natural gas ignition under shock tubes conditions [2,3]. This variability could lead to significant changes in compression ignition characteristics of NG and operational problems for diesel engines. However, little detailed information is available concerning NG ignition under DI diesel conditions and especially the influence of NG composition.

Fraser et al. [4] investigated autoignition of methane and methane-ethane mixtures with up to $15.8 \%$ ethane at pressures of $0.5-5.6 \mathrm{MPa}$, using a combustion vessel similar to that used here. To obtain a reasonable ignition time $(2 \mathrm{~ms})$ for a diesel engine, a temperature of $1250 \mathrm{~K}$ for methane and $1200 \mathrm{~K}$ for a $89.4 \%$-methane $10.6 \%$-ethane mixture was required. The ratio of ignition delay times for methane and methane-ethane mixture at the same temperature was approximately 2 . Fraser et al. also noted that the effects of pressure on ignition at a given temperature were small in comparison to temperature effects.

Westbrook et al. $[2,3,5,6]$ used a kinetics model to predict autoignition of methane, methane/ethane, and methane/ethane/propane mixtures in shock tubes, pulse combustors, and spark ignited engines. Although pressures and temperatures were lower than in this study, the kinetic model correctly described the sensitivity of methane ignition to addition of ethane and higher hydrocarbons. The present work extends the previous measurements and model predictions to more realistic NG blends and conditions representative of DI diesel engines.

\section{Natural Gas Fuel Blends}

Four mixtures listed in Table I were chosen to represent observed variability in NG composition. Pure methane represents an extreme that can occur when LNG is the source, delivering a methane content as high as $99.6 \%$ [7], while the mean mixture is a capacity-weighted mean [1]. The high ethane mixture represents an extreme high ethane content fuel typical of Colorado NG fuels [1], and the peak shaving gas is an example of natural gas supplied when propane/air peak shaving 
additions are made. Both the high ethane and peak shaving gases were also chosen to determine if ethane or propane addition might improve DI diesel ignition of NG. The extremes in propane and butane content were limited for these experiments to avoid fuel condensation in the fuel system and gas injector at room temperature, which could lead to uncontrolled variation in fuel composition.

The molecular weight, ratio of specific heats, laminar burning velocity, lower heating value of the fuel, and mass flux and energy flux for isentropic choked flow at $450 \mathrm{~K}$ and $20.7 \mathrm{MPa}$ (the injection conditions of the experiment) are all very nearly the same for the four fuel mixtures.

Table I. Selected natural gas mixtures for direct-injection combustion investigations.

\begin{tabular}{|c|c|c|c|c|}
\hline $\begin{array}{c}\text { Mixture } \\
\text { Constituent }\end{array}$ & $\begin{array}{c}\text { Methane } \\
\text { (\% Vol.) }\end{array}$ & $\begin{array}{l}\text { Mean } \\
\text { (\% Vol. })\end{array}$ & $\begin{array}{l}\text { High Ethane } \\
(\% \text { Vol. })\end{array}$ & $\begin{array}{l}\text { Peak Shaving } \\
(\% \text { Vol. })\end{array}$ \\
\hline $\mathrm{N}_{2}$ & 0 & 1.37 & 7.76 & 4.34 \\
$\mathrm{CO}_{2}$ & 0 & 1.21 & 1.43 & 1.13 \\
$\mathrm{CH}_{4}$ & 100.00 & 93.12 & 80.56 & 87.15 \\
$\mathrm{C}_{2} \mathrm{H}_{6}$ & 0 & 3.20 & 8.99 & 3.00 \\
$\mathrm{C}_{3} \mathrm{H}_{8}$ & 0 & 0.70 & 1.00 & 4.01 \\
$\mathrm{C}_{4} \mathrm{H}_{10}$ & 0 & 0.40 & 0.26 & 0.37 \\
Mole. Wt. & 16.04 & 17.36 & 19.02 & 18.58 \\
Methane No. & 100 & 91 & 75 & 94 \\
\hline
\end{tabular}

The methane numbers (MN) in Table I are determined from correlations given by Callahan et al [8]. Methane number provides an indication of knocking tendency of natural gas in spark ignition engines similar to octane number for liquid fuels, which may also make it a valuable parameter for diesel ignition similar to cetane number. Table I shows that methane has the highest $\mathrm{MN}$ and the high ethane mixture the lowest $\mathrm{MN}$. However, the correlation used for high ethane concentrations does not include terms for the inerts and butane. Therefore, to estimate the $\mathrm{MN}$ for the high ethane mixture the inert species and butane (which are nearly $10 \%$ of the high ethane mixture) were eliminated and the remaining constituents normalized to $100 \%$. 


\section{Experimental Apparatus}

The apparatus used consists of two major components: a constant-volume combustion vessel and a fuel injection system. The constant-volume combustion vessel is similar to one used previously [4,9-11] for diesel combustion studies. The new facilities allow remote, automated control of all operations and peak combustion pressures up to $35 \mathrm{MPa}$. Figure 1 shows a cross-section of the new combustion vessel, a disk-shaped combustion chamber with a $114.3 \mathrm{~mm}$ diameter and a $28.6 \mathrm{~mm}$ width. Sapphire windows permit full line-of-sight optical access to the chamber. Five interchangeable access ports and two injector ports are on its circumference, and its walls can be electrically heated to temperatures up to $250 \mathrm{C}$ to reproduce engine wall temperatures and prevent water condensation on the window surfaces. For these experiments the wall temperature was held at $177 \mathrm{C}$.

In the five interchangeable ports are valves for intake and exhaust, a surface gap spark plug, a pressure transducer, and a fan. The fan maintains a nearly uniform temperature in the chamber prior to injection as described by Siebers [9] and was run at $8000 \mathrm{rpm}$. Based on schlieren movies, fluid motion induced by the fan has little impact on the transient gas jet injection and diesel combustion process until injection is over. Furthermore, LDV measurements of fluid velocities show that the fan induced velocities are of the order of $0.8 \mathrm{~m} / \mathrm{s}$, more than two orders of magnitude smaller than gas jet velocities at the injector orifice.

The electronically controlled NG injector is based on one developed for an actual diesel engine. The fuel supply/injector system is capable of injecting gaseous fuels at injection pressures to $35 \mathrm{MPa}$ for injection durations as short as $2 \mathrm{~ms}$. Measurements of the rate of injection through the injector orifice(s) show that the start and end of injection are rapid, with a very nearly constant rate during the majority of the injection period. Under the choked flow injection conditions $\left(p_{\mathrm{O}}=20.7 \mathrm{MPa}, T_{\mathrm{O}}=450 \mathrm{~K}\right)$ in these experiments the nozzle orifice coefficient is 0.87 .

\section{Experimental Procedure}

The two step combustion process used here has been employed previously $[9,12,13]$ to simulate quiescent diesel TDC combustion processes in the constant volume combustion vessel. High pressures and temperatures are generated by the spark ignition and combustion of a lean premixed combustible gas. The premixed gas mixture includes $\mathrm{H}_{2}$ (5.9\% by volume), $\mathrm{C}_{2} \mathrm{H}_{4}(1.5 \%), \mathrm{O}_{2}(27.8 \%)$, and $\mathrm{N}_{2}(64.8 \%)$, selected so that the combustion products would have properties similar to air (e.g., $\left.21 \% \mathrm{O}_{2}\right)$, although concentrations of $\mathrm{H}_{2} \mathrm{O}(9.2 \%)$ and $\mathrm{CO}_{2}(3.1 \%)$ are higher than in 
normal air. Products of this first combustion event then cool by heat transfer to the chamber walls; when they reach a preselected pressure and temperature, the diesel injector is fired. The ensuing fuel jet autoignites and burns as in a diesel engine.

Figure 2 shows a typical diesel simulation pressure history. The initial density is $20.4 \mathrm{gm} / \mathrm{L}(p=2.77 \mathrm{MPa}, T=450 \mathrm{~K})$ in the premixed gas. The spark ignites the lean premixed charge (at time $=0$ in Figure 2 ) which then burns (the first pressure-rise in Figure 2). The premixed burn ends at $55 \mathrm{~ms}$, reaching a pressure of $10 \mathrm{MPa}$. The hot gases cool due to heat transfer, and when the desired state for the diesel experiment is reached, the fuel injector is fired. The time constant $(0.3-0.4$ sec) for cooling is long compared with injection duration, providing a nearly constant pressure-temperature environment during fuel injection. The second pressure-rise in Figure 2 (at $260 \mathrm{~ms}$ ) is caused by the autoignition and combustion of the NG fuel jet. The ambient gas at injection in this example had a bulk temperature $\left(T_{b}\right)$ of $1085 \mathrm{~K}$ and pressure of $6.47 \mathrm{MPa}$. The pressure-rise resulting from the NG fuel combustion in this example is only a fraction of that in an operating engine since a single hole injector tip was used versus a 6-8 hole tip used in an engine.

The temperature distribution during the cool down period was measured by Siebers [9] in a slightly smaller vessel to be uniform to $\pm 4 \%$ over the inner $90 \%$ of the chamber volume with fan induced mixing. Because of boundary layers and crevice volumes, the core gas temperature $\left(T_{c}\right)$, the mass averaged temperature over the inner $90 \%$ of the chamber, is higher than the mass-averaged bulk temperature $\left(T_{b}\right)$ determined from the pressure, density, and molecular weight. A simple relationship determines $T_{c}$ from $T_{b}$ and the wall temperature $\left(T_{w}\right)$,

$$
\mathrm{T}_{\mathrm{C}} / \mathrm{Tb}_{\mathrm{b}}=\mathrm{a}\left(1-\mathrm{T}_{\mathrm{W}} / \mathrm{T}_{\mathrm{b}}\right)+\mathrm{b}\left(\mathrm{T}_{\mathrm{b}} / \mathrm{T}_{\mathrm{W}}-1\right)+1
$$

The first term above accounts for boundary layers and the second term accounts for gases in crevice volumes which are assumed to be at the wall temperature. The constant $a$ is determined by an empirical fit to the measured temperature data. The constant $b$ is the ratio of the chamber crevice volume $\left(1.4 \mathrm{~cm}^{3}\right)$ and the total chamber volume $\left(293 \mathrm{~cm}^{3}\right)$. For this configuration and fan speed, $a=0.104$ and $b=0.005$, and $\mathrm{T}_{\mathrm{C}} / \mathrm{T}_{\mathrm{b}}$ ranges from 1.08 at $1500 \mathrm{~K}$ to 1.04 at $700 \mathrm{~K}$. Combustion vessel pressure, injector pressure, injector timing, and combustion luminosity were sampled at 500 $\mu$ intervals during the premixed burn, at $2000 \mu$ s intervals during the post diesel burn period, and at $24 \mu \mathrm{s}$ intervals during the diesel burn period. 


\section{Experimental Ignition Delay Determination}

The experimental ignition delay is determined as shown in Figure 3, indicating the net pressure-rise from the diesel burn versus time from the start of injection for three NG injections at core temperatures 1055, 1155, and 1255K, respectively. Contributions of wall heat losses to pressure change have been removed from the data shown in Figure 3. For each case, $13.9 \mathrm{mg}$ of the mean natural gas mixture was injected through a $250 \mu \mathrm{m}$ hole at an injection pressure of $20.7 \mathrm{MPa}$ over an $11 \mathrm{~ms}$ injection period. When the pressure-rise exceeds some preset value, that time relative to the start of injection is defined as the pressure-delay $\left(\tau_{p d}\right)$. For this work, the pressure-rise selected $(p=14 \mathrm{kPa})$ corresponds to a heat release from approximately $0.33 \mathrm{mg}$ of fuel, $2.5 \%$ of the total mass injected through the single orifice. In Figure 3 the dash-dot line corresponds to this $\Delta p$ used to define the pressure delays, which for these mean NG injections were 5.23, 2.16, and $1.13 \mathrm{~ms}$.

The pressure delay depends on kinetics and several physical processes, including primarily the finite rate of injection, pressure sensor placement, and rate of fuel/oxidizer mixing. The first of these physical delays is $0.33 \mathrm{~ms}$, the time required to inject $0.33 \mathrm{mg}(2.5 \%)$ of the total natural gas mixture, the amount of reacted natural gas required to raise the chamber pressure $14 \mathrm{kPa}$. The second physical delay, sensor placement, results from finite sound speed in the combustion vessel. The radius of the combustion vessel divided by the speed of sound is used to estimate this delay, giving a value of $0.08 \mathrm{~ms}$. Mixing times are extremely difficult to quantify and represent the largest source of uncertainties in comparing experimental observations with the model calculations. These delays are not believed to be additive, that is, injection, mixing, pressure wave propagation, and kinetics all occur simultaneously during the ignition process. However, the delays associated with the finite rate of injection $(0.33 \mathrm{~ms})$ and finite sound speed should be close to the minimum delay possible using this definition of pressure delay.

\section{Description of the Kinetics Model and Implementation}

Numerical calculations of ignition delay of the NG mixtures were carried out using the HCT model [14], which solves the coupled conservation equations of mass, momentum, energy, and chemical species. The reaction mechanism has been validated in previous studies $[2,3,15]$ and has described ignition and oxidation of all of the NG fuel components over a wide range of experimental conditions. The most recent listing of the complete reaction mechanism, with forward and reverse rate expressions, can be found in Pitz et al. [16]. 
Because the experiments are quite complex, the goal of the modeling study was simply to establish characteristic times for ignition of different fuel-air mixtures under the conditions of the experiments. Heat transfer is included as in previous studies [17] to give the correct cool down pressure decay rate. Kinetic calculations are begun at the vessel core temperature and measured pressure. Typically a relatively isothermal period is followed by a steep rise in temperature, with the induction time $\left(\tau_{i t}\right)$ defined as the time at which the steep temperature rise occurs.

\section{Test Conditions / Test Matrix}

Experiments were performed over a range of conditions centered on the TDC conditions of a direct-injection natural gas diesel engine, with a compression ratio of 23:1. At TDC the temperature is approximately $1150 \mathrm{~K}$ and the pressure is about 6.8 $\mathrm{MPa}$. Therefore, experiments in the combustion vessel were performed for core temperatures from 900 to $1600 \mathrm{~K}$ at the TDC density $(\rho=20.4 \mathrm{gm} / \mathrm{L})$. A single injection condition will be reported here: a single orifice nozzle with a $250 \mu \mathrm{m}$ diameter orifice and a 4.1 length/diameter ratio, a pressure of $20.7 \mathrm{MPa}$, a temperature of $450 \mathrm{~K}$, and a duration of $11-13 \mathrm{~ms}$. Model predictions of the induction time were made for the four NG fuels over the same range of core temperatures, using only stoichiometric mixtures.

\section{Results and Discussions}

Experimental results (shown as squares) are plotted versus the core temperature at the time of ignition in Figure 4. The experimental pressure delay data have been least-squares fit to the equation:

$$
\tau_{p d}=\sqrt{C^{2}+\left(A e^{B / T}\right)^{2}}
$$

where $C$ represents the shortest ignition delay possible $(0.41 \mathrm{~ms})$ based on the definition of pressure delay, established by the finite rate of fuel injection and finite sound speed. The dashed line in Fig. 4 is the least squares fit of Eq. (2) to the experimental data. The predicted induction times are plotted (solid lines) as a function of core temperature at the time of injection. Initial temperatures for the calculations were determined by assuming that a stoichiometric amount of fuel at $450 \mathrm{~K}$ is mixed with ambient gas initially at the given core temperature.

The measured and calculated results have similar overall trends. The effect of temperature is considerable over the temperatures most relevant to DI diesel 
engine operation (1000-1300K). The measured pressure delay in this range changes by an order of magnitude with a $20 \%$ change in $1 / T_{c}$, and at approximately $1100 \mathrm{~K}$ the predicted and measured ignition delays are equal. At temperatures above $1100 \mathrm{~K}$, predicted induction times become progressively shorter than the measured delays, while below $1100 \mathrm{~K}$ the computed induction delay times are longer than the measured pressure delays.

The differences between the numerical values of the predicted and measured delays are the result of factors not included in the model. At high temperatures the measured ignition delays approach a limiting value of $0.41 \mathrm{~ms}$ established by the finite physical delays, while the model calculations consider kinetics processes in fuel/air mixtures which are completely mixed. Below 1050K, the characteristic kinetic time scales are sufficiently slow that spatial non-uniformities in fuel/air concentration and transport processes not included in the model have a significant influence on the rates of ignition. However, in the intermediate regime, where the injection process is well established in advance of ignition and enough mixing can occur for stoichiometric fuel/air regions to exist, the kinetic model provides calculated ignition delay values similar to those measured in the experiment.

THE EFFECT OF NATURAL GAS COMPOSITION VARIABILITY: The best fits to the measured results were determined for the four NG fuels as shown in Figure 5, together with the comparable computed results. Addition of ethane, propane, and $n$-butane to pure methane decreases the ignition delay over the entire temperature range. The high ethane and peak shaving natural gases, which have the largest percentages of higher hydrocarbons, have the shortest ignition times. These trends are in agreement with results at lower pressures $[2-4,18]$ and are due to differences in the kinetic chain branching processes between methane and the higher hydrocarbon fuels. In particular, the methyl radical $\mathrm{CH}_{3}$ that dominates methane ignition is very difficult to oxidize, while alkyl radicals produced by larger fuels are much easier to consume, leading to faster rates of reaction. Further discussion of these points can be found in the references cited $[2,3,17]$.

Note that both the ordering of the computed ignition delay times of the four blends and their relative magnitudes are in close agreement with the experimental observations for temperatures between 1050 and 1250K. Even the subtle reordering of the high ethane and peak shaving mixtures seen between 1050 and $1100 \mathrm{~K}$ is similar between the model and experiments.

Pressure delays $\left(\tau_{p d}\right)$ and induction times $\left(\tau_{i t}\right)$ at a core temperature of $1150 \mathrm{~K}$ and the temperature required for a $2 \mathrm{~ms}$ ignition delay are shown in Table II for both 
experimental and computed results. As noted earlier, these conditions were chosen because they are representative of a NG diesel engine near TDC, and the values shown in Table II indicate a close agreement between the computed and measured results over this limited temperature range. At $1150 \mathrm{~K}$, pressure delays for the four fuels vary from $2.7 \mathrm{~ms}$ for methane to $1.8 \mathrm{~ms}$ for the high ethane and peak shaving gases, while calculated induction times range from 2.5 to $1.3 \mathrm{~ms}$ for the same blends. The core temperature required to achieve a $2 \mathrm{~ms}$ pressure delay (exp.) for the four fuels ranges from $1190 \mathrm{~K}$ for methane to $1140 \mathrm{~K}$ for the high ethane and peak shaving gases, while the corresponding predicted temperature range is $1160 \mathrm{~K}$ to $1120 \mathrm{~K}$.

The agreement between measured and predicted ignition delay trends indicates that natural gas composition effects are related primarily to changes in the kinetics of NG ignition rather than changes in physical properties. Therefore kinetics models can be used to assess relative effects of NG composition on diesel ignition of natural gas. At an engine speed of $1500 \mathrm{rpm}$, the $0.9-1.1 \mathrm{~ms}$ difference in ignition delay between an LNG derived natural gas (nearly pure methane) and peak shaving or high ethane natural gas blends corresponds to an $8-10$ crank angle

Table II. Pressure Delays and Induction Times (ms) at $T_{c}=1150 \mathrm{~K}$, and the temperature required for a $2 \mathrm{~ms}$ ignition delay.

\begin{tabular}{l|c|c|c|c|}
\multirow{2}{*}{ Fuel } & \multicolumn{2}{|c|}{$\tau(\mathrm{ms}) @ T_{c}=1150 \mathrm{~K}$} & \multicolumn{2}{c|}{$T_{c}(\mathrm{~K}) @=2 \mathrm{~ms}$} \\
& $\tau_{p d}$ & $\tau_{i t}$ & Exp. & Calc. \\
\hline Methane & 2.7 & 2.5 & 1190 & 1160 \\
Mean & 2.1 & 1.6 & 1160 & 1140 \\
High Ethane & 1.8 & 1.3 & 1140 & 1120 \\
Peak Shaving & 1.8 & 1.4 & 1140 & 1120
\end{tabular}

degree shift in the start of combustion. This shift is great enough to alter the rates of pressure-rise and the fraction of premixed versus mixing-controlled combustion in diesel operation, which in turn can produce performance and emissions changes.

Increasing concentrations of ethane, propane, and $n$-butane accelerate compression ignition of NG, but due to fuel condensation effects there are practical limits as to how much can be added when boosting fuel pressure to $21 \mathrm{MPa}$ for injection. Finally, measured and predicted effects of natural gas composition variations on ignition do not correlate well with the current practice of methane number determination [8]. The ordering of the methane number (from low to high) 
for the four fuels is: high ethane - mean - peak shaving - methane, while the ordering of their measured delays is: peak shaving \& high ethane - mean - methane.

\section{Conclusions:}

The minimum temperature required for reasonable diesel engine ignition delay ( $<2 \mathrm{~ms}$ ) for all four natural gas blends examined is approximately $1150 \mathrm{~K}$, slightly lower than the value reported by Fraser et al (1200K) for lower density conditions. It also corresponds closely to TDC conditions achieved in a DI compression ignition NG diesel engine. At high temperatures, measured ignition delays are limited by the rate of fuel injection; similar limits were observed by Siebers [9] for liquid fuels. Increasing the concentration of higher hydrocarbons in natural gas decreases the ignition delay by approximately $0.8 \mathrm{~ms}$ from that for pure methane under diesel engine conditions. Further increasing concentrations of propane and butane, however, could lead to their condensation in the injection system, resulting in fuel control problems. Good agreement between trends in the experimentally measured effects of natural gas composition on ignition delay and those predicted with a kinetics model indicate that variations in ignition delay produced by composition differences are due primarily to kinetic effects. This suggests that current kinetics models can be used to predict relative changes in ignition delay caused by natural gas composition variations. Finally, the Methane Number does not correlate well with measured and predicted ignition delay data under diesel engine conditions.

\section{Acknowledgments}

Support was provided by Gas Research Institute contracts No. 5086-260-1458 and 5091-260-2271. Experimental work was performed at the Combustion Research Facility, Sandia National Laboratories with the assistance and advice of co-workers: J. Bluemel, K. Hencken, G. Hubbard, and G. Hux. Kinetic modeling was supported by NSF grant CTS-9209747 and was carried out at the Lawrence Livermore National Laboratory under the auspices of the U.S. Department of Energy under contract No. W-7405-ENG-48. We are also grateful for the cooperation and interaction with Detroit Diesel and Diesel Technology Corporation in supplying the fuel injectors and providing information related to their natural gas engine development. 


\section{References}

1.) Liss, W.E., Thrasher, W.H., Steinmetz, G.F., Chowdiah, P., and Attari, A., "Variability of Natural Gas Composition in Select Major Metropolitan Areas of the United States," GRI Report GRI-92/0123, March 1992.

2.) Westbrook, C.K., Combust. Sci. Technol. 20:5-17 (1979).

3.) Westbrook, C.K. and Pitz, W.J. Combust. Sci. Technol. 33:315-319 (1983).

4.) Fraser, R.A., Siebers, D.L., and Edwards, C.F., Trans. SAE, 100, Sect. 4: 33-45 (1991) (SAE Paper 910227).

5.) Westbrook, C.K. and Pitz, W.J., "High Pressure Autoignition of Natural Gas/Air Mixtures and the Problem of Engine Knock," GRI Topical Report, GRI87/0264, Sept. 1987.

6.) Keller, J. O., and Westbrook, C.K., Twenty-First Symposium (International) on Combustion, pp. 547-555, The Combustion Institute, Pittsburgh, 1986.

7.) Liss, W.E. and Thrasher, W.H., "Natural Gas as a Stationary Engine and Vehicular Fuel," SAE Paper 912364, Int. Fuel and Lubricants Meeting, 1991.

8.) Callahan, T.J., Ryan, T.W. III, and King, S.R., "Engine Knock Rating of Natural Gases - Methane Number," ASME Energy-Sources Technology Conference \& Exhibition, 1993.

9.) Siebers, D.L., "Ignition Delay Characteristics of Alternative Diesel Fuels: Implications on Cetane Number," Trans. SAE, 94: 673-686 (1985) (SAE Paper 852102).

10.) Edwards, C. F., Siebers, D. L., and Hoskins, D. H. , "A Study of the Autoignition Process of a Diesel Spray via High-Speed Visualization," Trans. SAE, 101, Sec. 4, 1992 (SAE Paper 920108).

11.) Siebers, D. L. and Edwards, C. F., "Autoignition of Methanol and Ethanol Sprays Under Diesel Engine Conditions," Trans. SAE , 96, Sect. 5: 140-152 (1987).

12.) Oren, D.C., Wahiduzzaman, S., and Ferguson, C.R., "A Diesel Combustion Bomb: Proof of Concept," Trans. SAE, 93, Sect. 4, 1984 (SAE Paper 841358).

13.) Durrett, R.P., Oren, D.C., and Ferguson, C.R., "A Multidimensional Data Set for Diesel Combustion Model Validation: I - Initial Conditions, Pressure History and Spray Shapes," SAE Paper 872087, International Fuel and Lubricants Meeting, Nov. 1987.

14.) Lund, C.M., Lawrence Livermore National Laboratory, CA, UCRL-52504 (1987).

15.) Pitz, W.J., Westbrook, C.K., Proscia, W.M., and Dryer, F.L., Twentieth Symposium (International) on Combustion, pp. 831-843, The Combustion Institute, Pittsburgh, 1984. 
16.) Pitz, W. J., Westbrook, C.K., and Leppard, W.R., "Autoignition Chemistry of $\mathrm{C}_{4}$ Olefins Under Motored Engine Conditions: A Comparison of Experimental and Modeling Results," SAE Paper 912315, International Fuels and Lubricants Meeting, October 1991.

17.) Griffiths, J.F., Coppersthwaite, D., Phillips, C.H., Westbrook, C.K., and Pitz, W.J.,Twenty-Third Symposium (International) on Combustion, pp. 1745-1752, The Combustion Institute, Pittsburgh, 1990.

18.) Leppard, W. R., Combust. Sci.Technol. 43: 1-20 (1985). 


\section{Figure Captions}

1) Schematic cross-section of the combustion vessel.

2) An example pressure history of the diesel simulation process.

3) Examples of the pressure-rise from the direct-injection combustion of natural gas.

4) Pressure delays and induction times of mean natural gas.

5) Comparison of the pressure delays and induction times for the four natural gas fuel blends investigated. 
Fuel Injectors
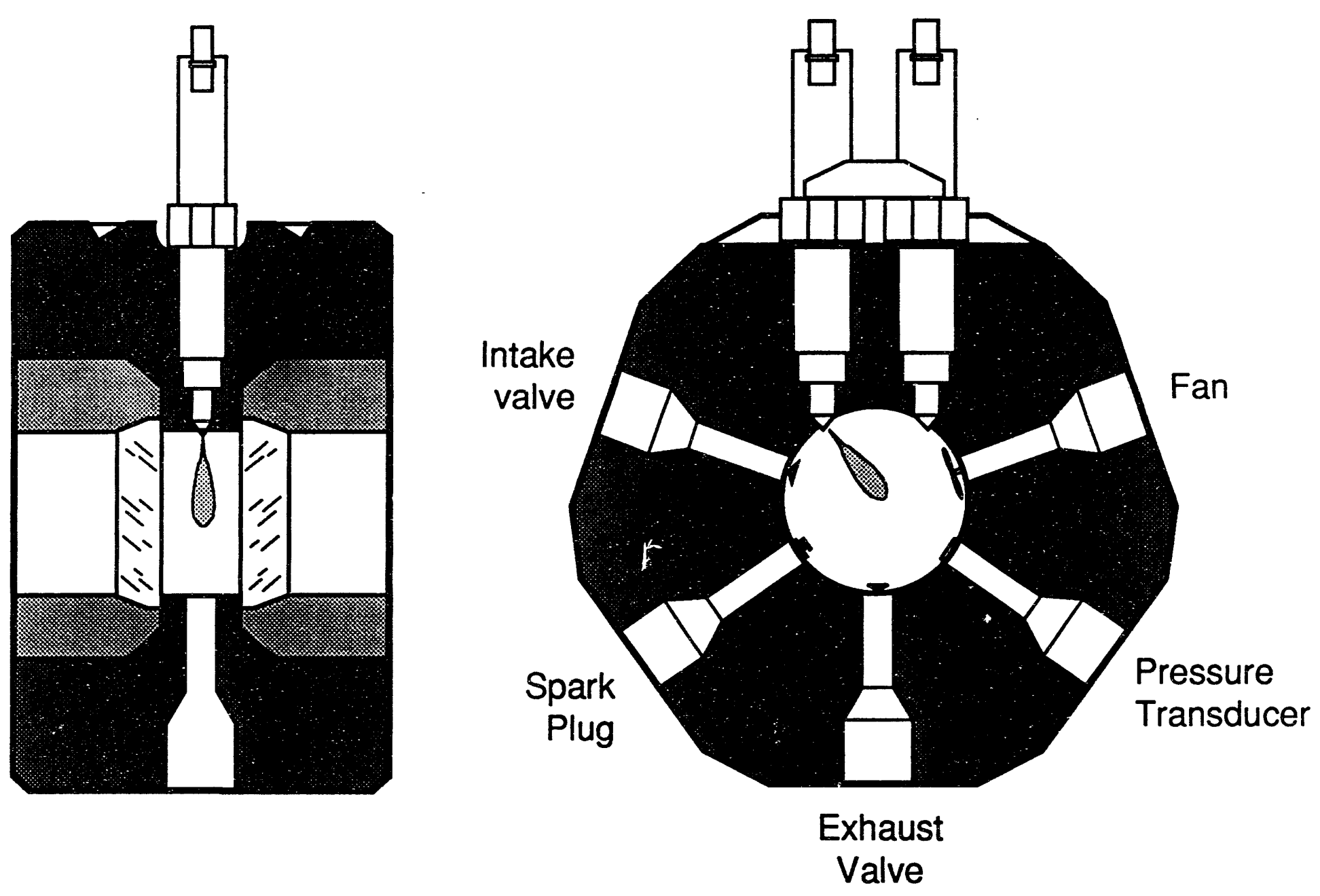


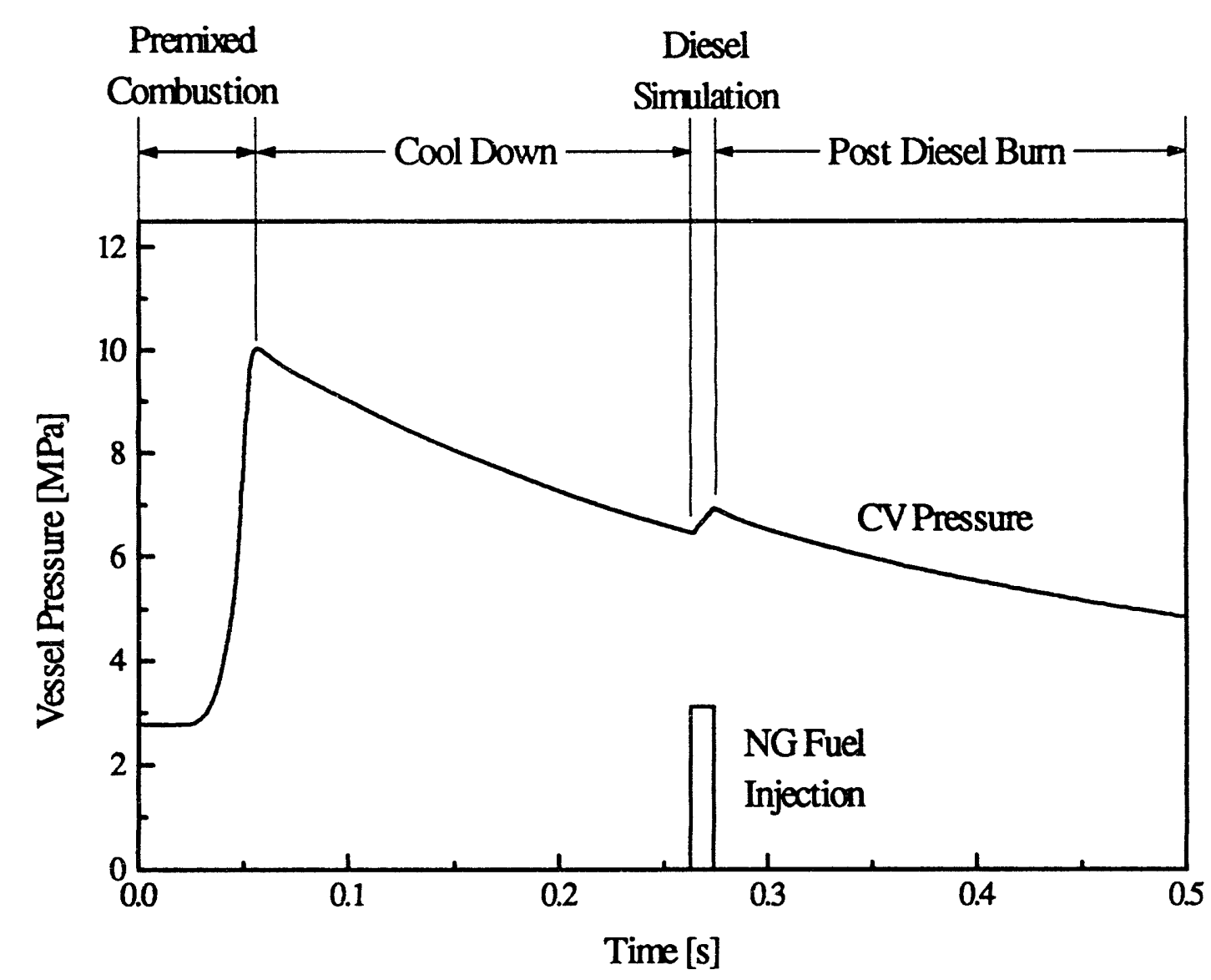




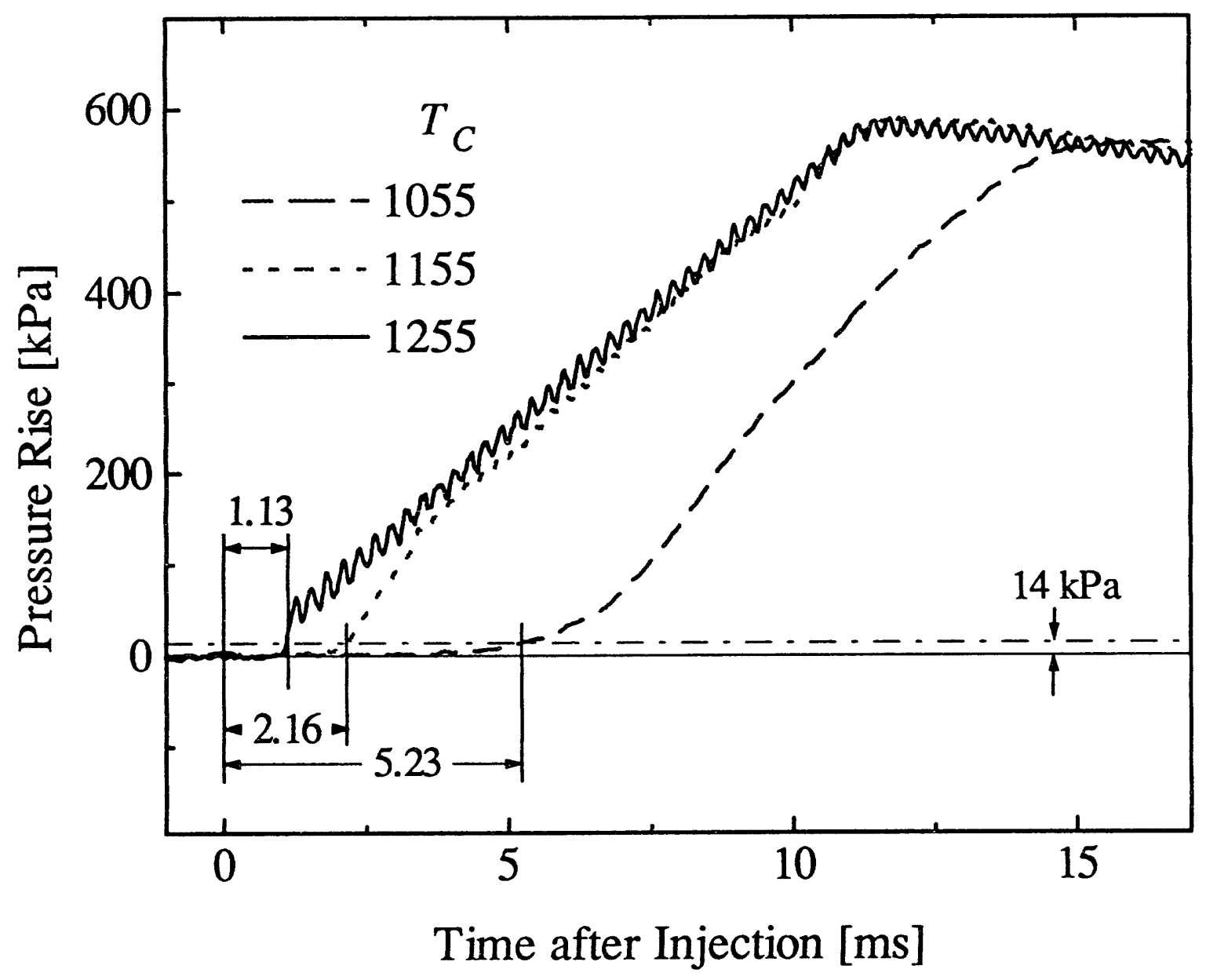




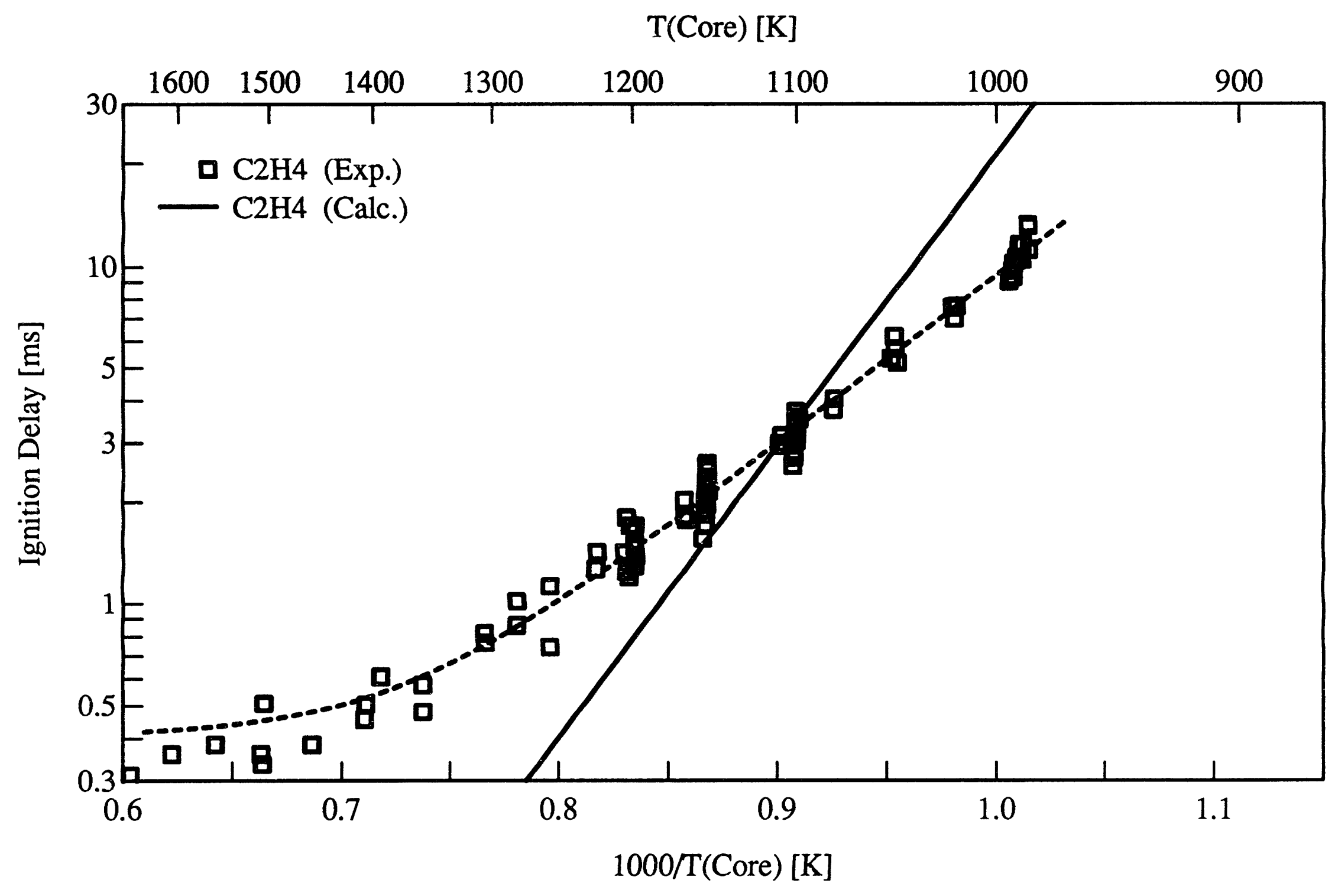




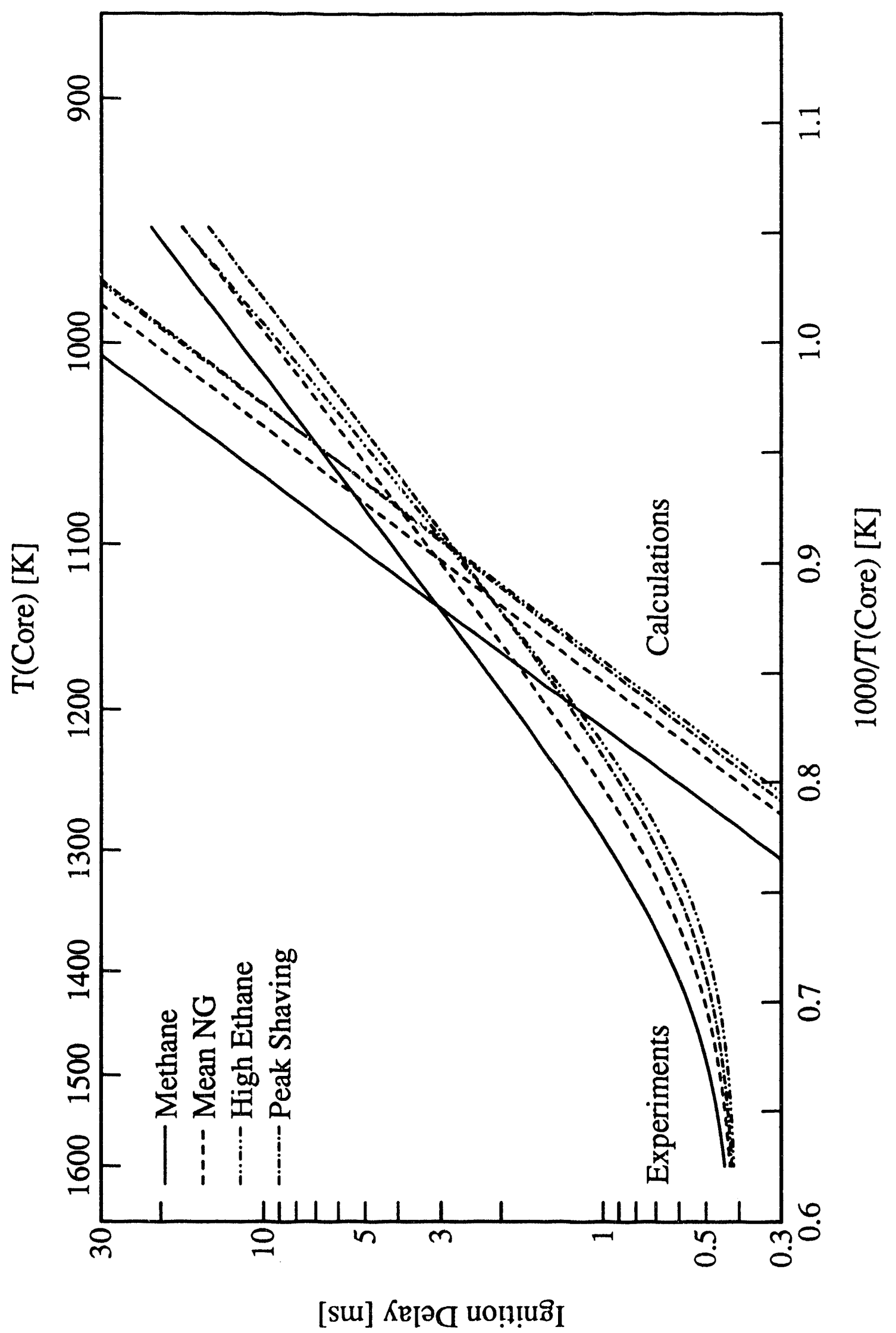



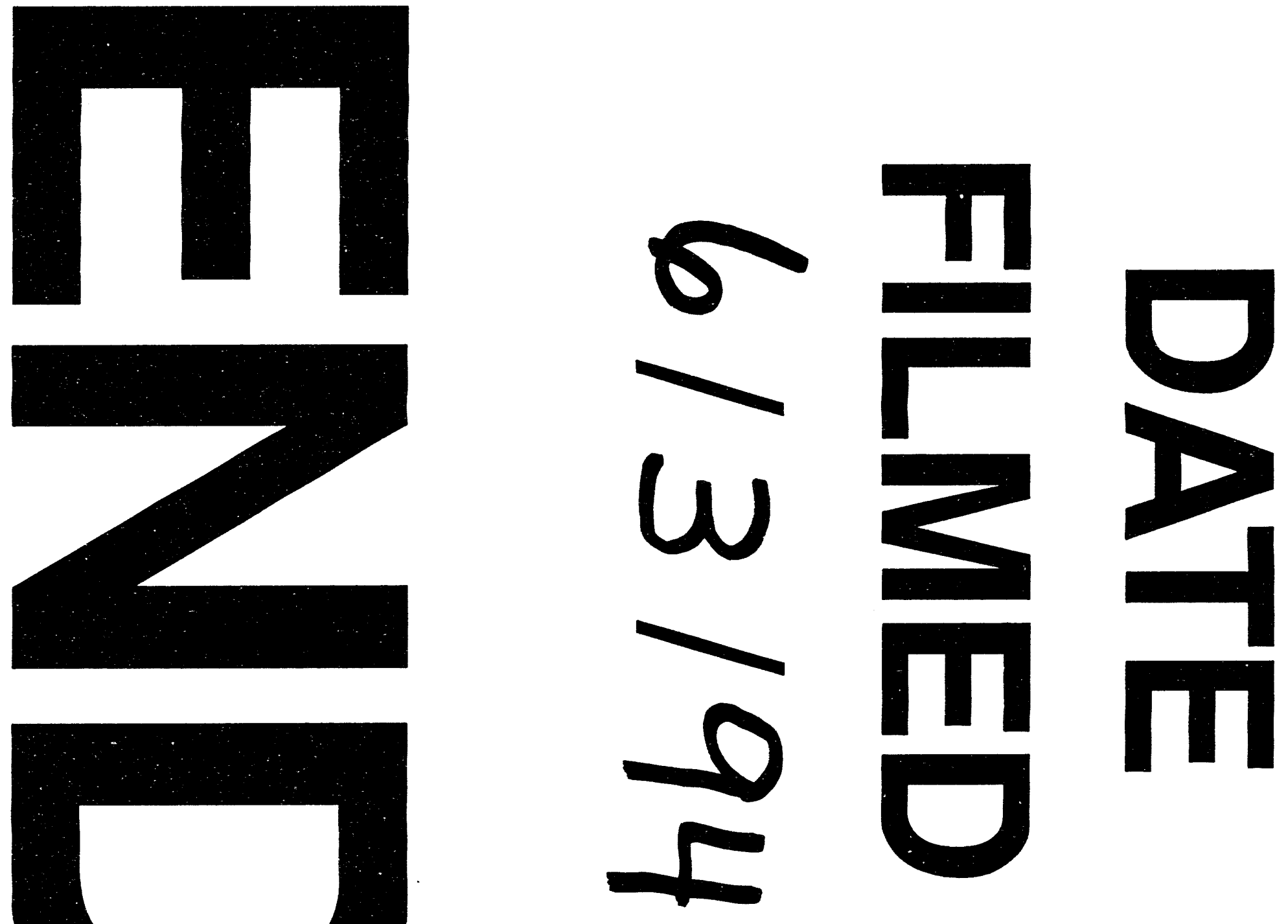
